\title{
Las relaciones entre la representación hegemónica de lo masculino y las subjetivaciones. Género y sexualidades en los relatos autobiográficos de integrantes del Colectivo Varones Anti-Patriarcales (Mendoza, 2013)
}

Relations between hegemonic representation of masculinity and their subjectivities. Gender and sexualities in autobiographical stories of members of the Collective of Anti-Patriarchal Men (Mendoza, 2013)

Santiago Zigliotto ${ }^{1}$

\begin{abstract}
Resumen
El tema de este artículo son las relaciones entre la representación hegemónica de lo masculino y las subjetividades. El mismo se abordó a partir del análisis de relatos autobiográficos de los miembros del Colectivo de Varones Anti-Patriarcales de Mendoza al año 2013. Las nociones utilizadas en el análisis son las de Género, visto en términos de los procesos de identificación y sexualidad(es). Las conclusiones indican que estos sujetos desarrollaron desidentificaciones con el modelo hegemónico de lo masculino a partir de las vivencias de la violencia como característica intrínseca a la sociabilidad masculina. Las sexualidades tienen un lugar preponderante en los procesos identificatorios, por tanto que gays y heteros relataron trayectorias desidentificatorias diferentes. Por último, la reflexión colectiva y la práctica política se manifestaron como parte de un proceso de desidentificación de la hegemonía, así como propone una instancia reidentificatoria con formas alternativas (¿contrahegemónicas?) de masculinidad.
\end{abstract}

Palabras clave: representación hegemónica de lo masculino - subjetividades - género - sexualidad.

\begin{abstract}
This article is about the relations between the hegemonic representation of masculinity and the subjectivities.It is addressed through the analysis of autobiographical accounts of members of the Collective of Anti-Patriarchal Men, Mendoza 2013.The notions used in the analysis are those of Gender, in terms of the processes of identification, and sexuality/ies.The findings indicate that these subjects developed disidentifications with the hegemonic model of masculinity from the experiences of violence as an intrinsic feature of male sociability. Sexualities have an important place in the identification processes, so that gay and straight reported having different paths.Finally, collective reflection and political practice demonstrated as part of a process of de-identification of hegemony and proposes an alternative (counter-hegemonic?) masculinity.
\end{abstract}

Key words: hegemonic representation of masculinity - subjetivities - gender - sexuality.

Fecha de recepción: Agosto 2015

Fecha de aprobación: Septiembre 2015

Tesista de grado de la carrera de Sociología de la Facultad de Ciencias Políticas y Sociales de la Universidad Nacional de Cuyo, Mendoza, Argentina. Miembro del Colectivo de Varones Anti-patriarcales de la Ciudad Autónoma de Buenos Aires. E-mail: santiagozigliotto@gmail.com 


\section{INTRODUCCIÓN}

La representación social preponderante de lo masculino es objeto de disputas hace varias décadas. Desde los años 80 han surgido teorías que dan cuenta de los distintos procesos de significación de diversas masculinidades. Estas teorías han cuestionado las pretensiones de universalidad y de neutralidad de la idea hegemónica de masculinidad, y han buscado comprender los efectos que la dominación masculina produce. El psiquiatra Luis Bonino Méndez fue uno de los primeros en conceptualizar la representación hegemónica de lo masculino y la definió con el nombre de Normativa Hegemónica de Género. Bonino explica: "Esta normativa supone un modelo proscriptivo y prescriptivo de conductas, valores, deseos, cuerpos y relaciones sociales que es externo y anterior a los sujetos, se les impone y los constituye como varones". (Bonino Méndez, 1998, 1).

El principal mérito respecto de la historización de las relaciones de género le corresponde a los movimientos feministas. Desde las décadas de 1960 y 1970 los feminismos, tanto en el campo de la práctica política como en el de la práctica teórica, fueron prolíficos en desarrollar categorías útiles para el cuestionamiento y la deconstrucción del orden de género establecido, orden que detenta una hegemonía profunda y estructural en las sociedades a nivel global.

Como parte de estos movimientos en la esfera latinoamericana contemporánea, los Colectivos de Varones Anti-Patriarcales de Argentina emergieron a partir del 2010 en distintos puntos del país. El primero se constituyó en La Plata, la ciudad capital de la Provincia de Buenos Aires. Un año más tarde nació el Colectivo en la ciudad de Mendoza, así como la Ciudad Autónoma de Buenos Aires y en la ciudad de Rosario, provincia de Santa Fe. Una de sus intenciones fue la deconstrucción personal y colectiva del modelo hegemónico de masculinidad, en pos de la despatriarcalización de las identidades sexuales y de género, masculinas en este caso.

Ahora bien, ¿es posible imaginar identidades que le disputen a la representación hegemónica de género su carácter de dominante cuando ellas mismas son el efecto de un proceso de subjetivación, en los propios términos de dicha representación hegemónica? Si la masculinidad hegemónica es representada en términos de un sujeto total, las subjetividades masculinas que esta engendra son resultados parciales e incompletas de dicho proceso de representación. ¿Qué pasa, entonces, en esta distancia entre la representación social y la realidad subjetiva? ¿Por qué, si no existen varones completos, la representación sigue significándolos como tales? ¿Cuáles son los mecanismos mediante los cuales la representación social de la masculinidad dispone a las subjetividades masculinas concretas a permanecer en la búsqueda inagotable de completitud? Y más importante aún: ¿qué pasa si intentamos torcer el curso de aquello que se presenta como inevitable?

El objetivo de la investigación fue comprender las relaciones entre la representación hegemónica de lo masculino y las subjetividades, estas se indagaron en varios relatos autobiográficos de varones integrantes del colectivo de Varones Anti-Patriarcales de Mendoza en el 2013, elaborados como parte de un proceso de reflexión en torno a sus propias masculinidades, en el marco de una actividad denominada "Taller de autobiografías", y a partir de las categorías de género(s) y sexualidad(es).

En el primer apartado el lector encontrará una descripción del Colectivo de Varones AntiPatriarcales de Mendoza, en tanto marco de relaciones sociales en las que surgen los relatos analizados, y un desarrollo de la experiencia del taller de autobiografías, en tanto práctica de la 
que surgieron los relatos autobiográficos de sus miembros. También notará que hablo en primera persona en esa instancia, ya que al momento de realizar las actividades yo era miembro activo del Colectivo de Varones de Mendoza, fui organizador del taller y mi autobiografía es uno de los relatos analizados. En este sentido, lo que se buscaba era superar la división sujeto cognoscente/objeto de conocimiento, para articularlos sobre la base de una experiencia personal, política y colectiva.

En el segundo apartado se plantearon las categorías utilizadas a partir de los aportes de Teresa de Lauretis $(1996,2014)$ : el género como representación; su compromiso con la subjetividad; las relaciones entre género y sexualidades, a partir de las lecturas freudianas de Laplanche (2015); una conceptualización de la dicotomía masculinidad/feminidad y su relación con las masculinidades y, finalmente, una descripción del procedimiento analítico con el que se abordaron los documentos.

El análisis de los documentos se desarrolló en el tercer apartado y se encontrarán tres instancias: por un lado la identificación con el género masculino en su modelo hegemónico, donde se habla de la asignación-asunción de dicho género; por otro lado, la desidentificación, donde se habla de las incomodidades de ser varón, de las sexualidades gays y heteros y sus implicaciones en las relaciones de género, de las violencias tanto ejercidas como padecidas en nombre de la "auténtica masculinidad" y de las relaciones con lo femenino; y finalmente en la tercera instancia se aborda la posibilidad de construir una masculinidad alternativa a partir de las prácticas y reflexividades colectivas en torno de estas cuestiones.

\section{EL COLECTIVO DE VARONES ANTI-PATRIARCALES DE MENDOZA}

El Colectivo de Varones Anti-Patriarcales de Mendoza comenzó a trabajar a fines del 2011 y estuvo constituido por varones que se juntaban con la intención de problematizar su masculinidad. El objetivo del trabajo que desarrollaron se manifestó en la puesta en tensión de los tres términos de su nombre: una práctica política entendida como Colectiva, en la necesidad de entablar redes y relaciones entre sujetos; la condición de estos sujetos es haber sido socializados como Varones, en tanto que el trabajo de deconstrucción se centra en la masculinidad, principalmente en su versión hegemónica; y Anti-patriarcales en la medida en que buscan subvertir el orden de dominación masculina de las relaciones de género.

Así como las feministas radicales italianas de las décadas de 1960 y 1970 desarrollaron sus grupos de reflexión y concientización, el Colectivo de Varones Anti-Patriarcales de Mendoza pretendía generar instancias de encuentro para que sujetos autodefinidos como varones pudieran interrogarse acerca de la"naturaleza" de su autodefinición, respecto de los efectos de dicha autorrepresentación y relativo a estrategias políticas de trasformación de una situación que consideran opresiva: el cis-hetero-patriarcado.

En el manifiesto que desarrollaron en los primeros meses de su accionar definieron tres ejes centrales de trabajo: teórico, político y emocional. Estos tres ejes son tres dimensiones del mismo objeto, principalmente las subjetividades biomasculinas y la dominación masculina en general, y están en relación de interdependencia.

Los miembros del Colectivo de Varones Anti-Patriarcales de Mendoza tuvieron vínculos afines a espacios de militancia social: feminismos, LGBT, veganismo, trabajo barrial. Además varios de ellos eran estudiantes de la carrera de Sociología: en ese sentido tanto la Facultad de Ciencias Políticas y Sociales de la UNCuyo y sobre todo la carrera de Sociología, como la 
Subsecretaría de Género y Diversidad Sexual del Centro de Estudiantes de dicha facultad, creada en el 2010 en el marco de la Lucha por el Matrimonio entre personas del mismo sexo, representó un espacio de encuentro para estos sujetos.

Los miembros del Colectivo de Varones Antipatiarcales pertenecían a hogares de clase media y trabajadora en cuanto a recursos económicos y nivel de estudios, viven en el Gran Mendoza, y eran estudiantes, investigadores y artistas, lo que permitió un cruce de subjetividades vinculadas a lo teórico, a lo político y a lo artístico, en el marco de los movimientos sociales. Las edades de los mismos iban desde los 18 hasta los 40 años, con una mayor concentración entre los 23 y los 25 años. La mayoría de ellos eran solteros, los que estaban en pareja no ejercen paternidades y sus orientaciones sexuales eran multiples, gays y heteros, principalmente.

El colectivo de Varones de Mendoza desarrolló diferentes actividades político-culturales entre el 2011 y 2014, principalmente ciclos de cine-debate, talleres en escuelas, participaron de espacios de articulación como la Campaña por el Derecho al Aborto Legal, Seguro y Gratuito de Mendoza y en la Mesa contra la Trata de personas, así como también talleres "internos" vinculados a la reflexión colectiva acerca de la identidad masculina. También participaron en los Encuentros Nacionales de Colectivos de Varones, y fueron sede del II Encuentro Nacional, en el 2013. De esos talleres internos es que deriva en "taller de autobiografías", del que se desprenden los documentos autobiográficos analizados.

\subsection{La experiencia del taller de autobiografías}

La escritura de una autobiografía se presentó como una reconstrucción que apuntaba a conocer las interpretaciones de determinados hechos del proceso de socialización como varones.La narración del pasado, aquellos eventos que decidimos recordar u olvidar, son construcciones desde el presente; en ella se juegan los significados en donde interpretamos nuestra situación actual. El trabajo con el espacio biográfico, en términos de Arfuch, habilitó la construcción de una identidad narrativa que da forma a lo informe de la experiencia anclándolo en la temporalidad: el tiempo mismo se torna humano en la medida en que es articulado en un modo narrativo (Arfuch, 2010, 35). De este modo, el carácter configurativo de la narrativa se articuló al carácter narrativo de la experiencia y se plantó como una potente herramienta de análisis social tanto el reconocimiento de la artificialidad de la construcción del yo como en la pregunta por la construcción de un "nosotros".

En el momento en el que escribí mi autobiografía yo estaba formando parte activa del Colectivo de Varones Anti-Patriarcales de Mendoza, y ya que muchos de los conceptos que me formé y las preguntas que elaboré derivan directamente de mi práctica política y de mi intención de reflexión teórica alrededor y en el marco de la práctica política, decidí compartir mi autobiografía con mis compañeros. Les propuse, además, que ellos escribieran la suya.

La experiencia de escribir la propia autobiografía fue interesante en la medida en que, una vez expuesta la consigna, todo cuanto refiriera a ella era material de análisis: desde las resistencias a escribirla, hasta las dificultades para recodar, incluso el agobio o la fatiga que varios manifestamos sentir cuando terminamos de escribirlas. Escribir nuestra propia vida era ponerle palabras a nuestras experiencias, con el fin de ser compartidas.

La segunda parte de esta primera instancia constó de otro momento: el leer las autobiografías de nuestros compañeros. El Colectivo de Varones Anti-Patriarcales de Mendoza buscaba 
contemplar la dimensión de la afectividad y de la emocionalidad, ya que es una esfera en la que la masculinidad configuró nuestras posibilidades de relación, de encuentro y de contacto. Esta instancia permitió entender la potencia política de la propia experiencia -como varón y como sujeto social-, así como entender cómo cada uno en carne y alma propia había vivido determinados eventos y había interpretado determinados hechos que nos llevó a la necesidad de encontrarnos con otros varones para reflexionar en torno a lo que nos pasaba en tanto tales.

La estrategia metodológica de investigación del problema que pretendía abordar constó del análisis de los relatos a la luz de ciertas categorías teóricas. A continuación se expondrán tanto las categorías como el procedimiento de trabajo.

\section{NOCIONES PARA EL ANÁLISIS Y PROCEDIMIENTO ANALÍTICO: GÉNERO(S), SEXUALIDAD(ES) Y SUBJETIVACIÓN}

\subsection{La categoría de Género}

Probablemente una de las categorías más potentes de la llamada segunda ola del movimiento feminista es la de Género, y su surgimiento está vinculado a la explicación y la subversión de la subordinación de "la mujer", principalmente en las sociedades occidentales contemporáneas en una primera instancia.

La trayectoria teórico-política de dicha categoría, central en la crítica al Sujeto moderno, se remonta a Simone de Beauvoir y su tematización de la mujer como "lo otro", "el otro sexo", desde la perspectiva existencialista y con influencia hegeliana (Beauvoir, 1995). Luego, la conceptualización de la noción de patriarcado para el feminismo radical, en el contexto de la emergencia de los nuevos movimientos sociales, dentro de ellos el movimiento de liberación de la mujer; las relaciones entre patriarcado y capitalismo, en los intentos del feminismo socialista de establecer diálogos entre las nociones de género y clases sociales; los aportes de los feminismos del sur, del feminismo negro y el lesbianismo, los feminismos de los márgenes, la definición del sistema sexo-género; hasta incluso el ingreso de la noción de género en las academias, tanto feminismos académicos como institución de investigación de las mujeres, fueron algunos de los aportes en torno a esta categoría.

Esta proliferación de discursos feministas permitió el cruce con las perspectivas estructuralistas y posestructuralistas. Este encuentro giró en torno a la relación entre estructura y sujeto, principalmente, como sujeto de sexo/género/deseo. Gracias a los aportes del psicoanálisis lacaniano se pudo pensar la dimensión del deseo, del goce y de las estructuras psicológicas en donde se estructura dicho deseo en relación con el poder. Además, el concepto de lenguaje, clave para el pensamiento posestructuralista, habilitó una amplia variedad de preguntas que permitieron ligar estas relaciones entre estructuras y sujetos (Butler, 2001). Las nociones de ideología y de interpelación del pensamiento althusseriano, así como el estadio del espejo lacaniano fueron algunas de las explicaciones de esta relación (Althusser, 1988). Los conceptos de dispositivos y tecnologías de sexo, así como los discursos relativos a sexo en los análisis de Michel Foucault centraron la base para estas confluencias entre posestructuralismos y feminismos (Foucault, 1991).

\subsection{Género como representación: aportes de Teresa de Lauretis}

En el encuentro entre lecturas feministas y pensamiento posestructuralista, la lingüista y filósofa ítalo-norteamericana Teresa de Lauretis propuso un análisis de los dispositivos y 
objetos de la cultura entendidos como tecnologías del yo/tecnologías de género. En su texto, La tecnología del género, la autora estableció cuatro proposiciones acerca del género: (1) el género es una representación; (2) la representación del género es su construcción; (3) la construcción del género continúa hoy tan diligentemente como en épocas anteriores; (4) en consecuencia, paradójicamente, la construcción del género es también afectada por su deconstrucción (De Lauretis, 1989).

El género es la representación de una relación que establecen entidades que están previamente construidas como clases -en el sentido de clasificación-, con las que se tiene una relación de pertenencia. A los individuos se les asigna un género en términos de la posición que ocupen en una relación social particular, predeterminada y predicada en una oposición estructural -rígida- de dos sexos biológicos, lo que el feminismo radical Ilamó el sistema sexo/ género. En la cultura se significan lo masculino y lo femenino como dos categorías complementarias y mutuamente excluyentes a las que los seres humanos deben pertenecer (De Lauretis, 1989, p. 11).

El género representa no el sistema de relaciones reales que gobiernan la existencia de los individuos, sino la relación imaginaria de estos individuos con las relaciones reales en las que ellos viven (De Lauretis, 1989, p. 5). Esto significa que los géneros no pertenecen al orden de las cosas, de la naturaleza, de lo eterno, inmutable, innato; sino que más bien derivan de un modo particular de representarnos, de imaginarnos, determinado entramado de relaciones. En otras palabras, la construcción del género es tanto el producto como el proceso de su representación (De Lauretis, 1989, p. 11).

El género, en tanto producto y proceso de representación, opera en su compromiso con la subjetividad. Si para Althusser "toda ideología tiene la función (que la define) de constituir a los individuos concretos en sujetos", para De Lauretis "el género tiene la función (que lo define) de constituir individuos concretos como varones o mujeres" (De Lauretis, 1989; p. 6). De este modo, De Lauretis establece la relación entre el género y la ideología, donde más bien el género es una instancia primaria de ideología.

Al caracterizar al género como una instancia primaria de la ideología, puede teorizarse como una fuerza político-personal. Si la representación social de género afecta a su construcción subjetiva, esa misma construcción subjetiva, y cómo esta se autorrepresente, afecta la representación social y posibilita un margen de acción y de autodeterminación en el nivel subjetivo e individual de las prácticas cotidianas y micropolíticas (De Lauretis, 1989).

De este modo, el género supone un proceso de subjetivación, el mecanismo de que un individuo sea representado como perteneciente a una categoría de género. Precisamente en el punto de su constitución, en la instancia de la autorrepresentación se encuentra un margen de agencia, ya que ese género que se le asigna lo compromete subjetivamente: el sujeto debe asumirlo o puede rechazarlo. Aquel momento personalísimo de interpelación es un momento político-ideológico por excelencia.

\subsection{Sexualidad, identificaciones de género y subjetividad}

El mecanismo de interpelación ideológica de género implica un doble proceso: de asignación, el género nos viene de los Otros, y de asunción, de autorrepresentación en aquellos términos. En el orden de la subjetividad, de acuerdo con las categorías psicoanalíticas de sujeto, el género se manifiesta en forma de identificaciones. 
El género es una manifestación del yo consciente o preconsciente. A pesar de que viene del Otro, pues es asignado por los padres, las madres y los médicos a menudo antes de nacer, requiere una acción de parte del niño o la niña, él o ella juegan un rol en la construcción del su yo: lo deben asumir, es decir, deben hacerlo propio por medio de un proceso de identificación. La identificación como niño o niña, ya que ninguna otra alternativa se ofrece en la niñez, generalmente se lleva a cabo muy temprano, aun antes de descubrir las diferencias anatómicas. En los años subsiguientes, esa identificación puede ser confirmada y convertirse en una identidad de género o puede ser cuestionada, rechazada o transferida a otro género. La identificación es definida por Laplanche y Polantis como el proceso psicológico mediante el cual un sujeto asimila un aspecto, una propiedad, un atributo de otro y se transforma, total o parcialmente, sobre el modelo de este. La personalidad se constituye y se diferencia mediante una serie de identificaciones (Laplanche y Polantis, 2015).

El psicoanalista Jean Laplanche, en su trabajo acerca de la sexualidad como una seducción generalizada sostiene que a lo largo de la vida se realizan múltiples identificaciones de género, eso significa que el género en el orden de los sujetos es múltiple. Sin embargo, la categoría social del género, el género no tanto como identificación sino como representación, es binaria y está estructurada genitalmente (Laplanche, 2001).

La sexualidad, a pesar de que tampoco es innata, no está presente en el cuerpo cuando nacemos sino que viene del Otro, de los adultos, y es un efecto de seducción, es implantada en el recién nacido, el infante, un ser sin lenguaje e inicialmente sin yo, por las acciones necesarias del cuidado materno. En la madre y otros/as cuidadores/as adultos/as estos actos están acompañados por inversiones afectivas conscientes y también por fantasías inconscientes que se transmiten al bebé como mensajes o significantes enigmáticos. En el bebé estos significantes enigmáticos intraducibles están sometidos a la represión primaria y constituyen el primer núcleo del inconsciente del niño o de la niña. Cuando el niño o la niña crece y el yo se forma o desarrolla se producen traducciones parciales, pero estas también dejan residuos sin traducir que permanecen escritos en el aparato psíquico del individuo como huellas mnémicas o memorias irrecordables de excitaciones y placeres del cuerpo. Tales residuos enigmáticos actúan, siguen vivos aunque sin ser detectados y se reactivan en la sexualidad adulta a veces bajo formas que nos parecen vergonzosas o inaceptables. De esto provienen los conflictos, ya sean morales o neuróticos, que todos experimentamos en nuestra vida sexual.

En suma, mientras que la sexualidad es implantada como una excitación psicofísica que el/la bebé no puede controlar o metabolizar, y por tanto, permanece inconsciente, la identificación de género es un proceso consciente o preconsciente en donde el niño o la niña participan activamente. De este modo, podemos pensar las relaciones entre sexualidad y género como el resultado de la articulación de tres factores: género, sexo (anatómico fisiológico) y lo propiamente sexual, es decir, la sexualidad como efecto de la represión, la fantasía y el inconsciente (De Lauretis, 2014).

La hipótesis de De Lauretis es que el género como representación encuentra en las nociones psicoanalíticas de "complejo de castración", "complejo de Edipo", entre otras, instrumentales en su construcción, que lo afirman y reafirman cuando es necesario, dichos "esquemas narrativos preformados de la cultura" (De Lauretis, 2014) son aliados del género, y su función, similar al proceso que Freud describió en El malestar en la cultura es reprimir lo propiamente sexual. 
Entonces, si el género produce mujeres y varones, identidades, compartimentos y jerarquías sociales al reprimir lo sexual, lo sexual reprimido debe ser tenido en cuenta con un componente problemático y no reconocido de la identidad y de la sociedad.

\subsection{Lo masculino en su representación hegemónica y las masculinidades}

Como se desprende de los apartados anteriores, la masculinidad, el género masculino, viene del Otro y uno en tanto sujeto de género, asume el total de los efectos de ser representado como varón a partir de reconocerse, de asumirse y reasumirse. Esto se hace patente o se materializa en el caso que analizaremos.

Bourdieu (2000) da elementos claros para pensar la cuestión de cómo es significado sociohistóricamente lo masculino y plantea que la virilidad, en tanto condición de masculinidad, supone una virtud, un honor, una nobleza, un deber-ser que se impone como natural e indiscutible. Sin embargo, la virilidad no se construye con referencia a sí misma sino que es un concepto relacional, ubicado en el extremo opuesto al de feminidad, mediante el mecanismo de repudio, como lo denomina Judit Butler (1990). Como vemos, la virilidad es un concepto eminentemente relacional, construido ante y para los restantes hombres y contra la feminidad, en una especie de miedo de lo femenino, y en primer lugar en sí mismo (Bourdieu, 2000, p. 71).

De este modo, podemos decir que la representación hegemónica de lo masculino está construida en función de estos esquemas narrativos preformados por la cultura, lo masculino hegemónico es anterior a los sujetos masculinos, anterior a las masculinidades, y las constituye como tales. Sin embargo, el contenido concreto que para cada sujeto representa lo masculino, y su propia masculinidad, no puede ser rastreado por fuera de la formación social y del momento histórico al que dicho sujeto pertenece, ni por fuera de las relaciones sociales de identificación/desidentificación que haya establecido a lo largo de su vida.

El trabajo analítico con los relatos autobiográficos constó de la búsqueda de elementos relacionados con las categorías de Género, rastreado en términos de Identificación (luego Des-identificación y Re-identificación), y Sexualidad/es. En este punto, otra categoría que surge con relevancia es la de Violencia. Y en interrelación profunda con ellas, las nociones de lo masculino/la feminidad.

En los relatos, las múltiples identificaciones de género se presentaron como móviles, en permanentes desplazamientos y tensiones, y en tal sentido es que la búsqueda por las des-identificaciones, sobre todo del modelo hegemónico de lo masculino, y luego, las reidentificaciones que esos movimientos habilitaron, son un elemento clave para entender las trayectorias de estas subjetividades.

Para finalizar, una categoría que surgió con fuerza de los relatos es la de Violencia. Si bien por la misma entendemos una forma de la violencia característica de la formación identitaria genérica y que reactualiza la significación sociológica de la dicotomía masculinidad-feminidad, la violencia simbólica, cuyo principal tratado está hecho por Pierre Bourdieu (2000), en los relatos analizados la violencia no surge estrictamente relacionada con su dimensión simbólica, sino que se presenta en distintas escenas y narraciones histórico-biográficas y toma formas concretas: violencia sexual, violencia verbal, violencia física y violencia psicológica, entre otras. Estas diversas formas de experimentar tanto el padecimiento como el ejercicio de la violencia,"justificada" en la (re)producción de la masculinidad, permiten sostener el carácter 
constitutivo de la misma en la identidad masculina, o en términos de Bourdieu, la virilidad en su verdad como violencia actual o potencial (Bourdieu, 2000).

Luego del rastreo de dichas categorías, el trabajo analítico constó de la elaboración de una narrativa analítica que conservara la estructura, principalmente cronológica e históricobiográfica de los relatos. De este modo se pretendió ejemplificar la presencia de estas categorías y sus relaciones con fragmentos de los relatos que las reflejan o cristalizan.

\title{
3. RECORRIDOS (DESDE/RE)IDENTIFICATORIOS: CAMINOS EN LA (DE)CONSTRUCCIÓN DE LA MASCULINIDAD
}

\subsection{La masculinidad asumida: la identificación}

Las identificaciones de género de los miembros de los Colectivos de Varones Anti-Patriarcales de Mendoza, en una primera instancia, tiene que ver con el hecho de haber sido leídos como varones, de haber entrado al espacio social a condición de habitar el lugar asignado y asumido, de haberse constituido como sujetos pertenecientes al género masculino. En estos relatos, la identificación con el género asignado corresponde con los períodos de la niñez y de la adolescencia. A continuación transcribiré fragmentos de los relatos que reflejan dicha identificación:

"Mi infancia pasó rápido, varonilmente feliz" (Laurato, 37 años).

"Mi infancia fue normal, yendo a la iglesia todos los domingos, jugando mucho con mis hermanxs y primxs, ya que todos tenemos edades muy cercanas. (...) En mi época de estudiante de primaria era un chico 'normal' aceptable por todos los estereotipos machistas de nuestra sociedad, tenía amigos varones, jugaba a la pelota y todas las cosas 'normales' de los niños de esa edad" (Israel, 21 años).

La asunción del género asignado -el masculino- es el punto de partida en todos los relatos.

\begin{abstract}
"Mi adolescencia: se separan mis padres y yo asumí algunos roles otorgados: el hombre de la casa: me oponía a mi abuela, cuidaba a mis hermanas, era ley no transar en el boliche, era ley vincularse con la religión, era ley proteger a mi madre, era ley odiar a mi padre, era ley andar bien en la escuela y negar la sexualidad" (Juan, 30 años).
\end{abstract}

"Solo me limitaba a estudiar y a medianamente seguir los patrones de varón que se me imponían" (Nahuel, 18 años).

Sin embargo, esta identificación no es total ni incuestionada. Los siguientes relatos son un ejemplo de desidentificaciones tempranas con ciertas características asociadas a la masculinidad, en contraposición a sus reversos, asociados a la feminidad:

\footnotetext{
"Hoy estoy relativamente en paz con mi ser varón pero no siempre fue así. Durante muchos años reduje la masculinidad a ciertas características peyorativas: los varones son sucios pienso en mi papá llegando chivado de hacer ejercicio y querer abrazarme yo sentir asco-, son rudos, son brutos - pienso en un amiguito que rodaba en el piso y se golpeaba pero no lloraba y yo me preguntaba cómo hacía para que no le doliera- son ásperos-pienso en cuando dormía en la cama de mis padres y no quería dormir en el medio porque las piernas peludas de mi papá me daban asco-son invasivos - pienso en mi papá paseándose en bolas por mi casa y tirándose pedos no importa en frente de quién esté-. En pocas palabras, no quiero ni siento que tenga ninguna de esas características en mí y si las tengo y me las encuentro, me avergüenzan" (Sebastián, 23 años).
} 
"(...) Eso, sumado al rechazo por parte de mi padre hizo que cada vez tenga miedo de los hombres. A partir de esa edad (6-7 años) no sabía cómo tratarlos (...) En mi vida, la figura femenina representada en muchas personas, hermanas, madre, amigas, vecinas, era más fuerte y me transmitía más confianza. Y esa dicotomía Hombre = frialdad y miedo/Mujer = amor y cariño empezó a internalizarse en mi mente (Nahuel, 18 años).

En el transcurrir de los relatos va a empezar a emerger que la principal tensión de estos varones en torno a la identificación con el ser "varón" está dada por su vínculo intrínseco con procesos que van tomando formas de violencia. Como sostiene Bourdieu, al igual que el honoro la vergüenza, la virilidad tiene que ser revalidada por los otros hombres, en su verdad como violencia actual o potencial, y certificada por su pertenencia al grupo de los "hombres auténticos" (Bourdieu, $2000,70)$. Alguna forma de violencia va a atravesar a todos los relatos autobiográficos y delimita las relaciones específicamente entre varones, en dos sentidos: se la ejerce "o" se la padece:

"Cagarnos a piñas, que los más grandes nos peguen a nosotros, pegarle a los más chicos, abusar de las chicas cuando se amontonan para comprar en el buffet, tocar culos, rozar tetas, todo dejo pasar a mi alrededor sin problematización alguna. Llega el fútbol nuestro de cada día, el trato jerárquico y abusivo de los varones más grandes, las mujeres -lo femenino-como "lo otro", la complicidad ante la violencia y la discriminación, la homofobia violentísima, las tribus, los bailes" (Francisco, 25 años).

"Ya en la escuela primaria llegó el horror que me marcó y del cual he meditado y pensado muchos años de mi vida: un compañero repetidor que se abusaba de mí, hostigándome, aprovechando las veces en las que nos encontrábamos solos para apoyarme, yo siempre me largaba a llorar, le decía que no lo haga más, él decía que no le contara a nadie (...) yo tenía 8 años (...). Entre los 6 y los 11 años lloraba mucho, no me bancaba ningún tipo de violencia, no me gustaban los apodos sin mi consentimiento, no me gustaban los juegos bruscos, no me gustaba hostigar a nadie. (...) En la secundaria por esa cuestión chota de no querer quedar afuera alli iba el pelotudo siguiendo a la masa, hostigando a otros, hasta que por una cuestión de justicia, por así decirlo, me pasé al bando de los ñoños y nerds de la secundaria, ahora yo recibía el bullying feroz" (Samuel, 25 años).

El reconocimiento de la violencia constitutiva de los vínculos desde el lugar de varón representan una instancia de desidentificación, no con "la masculinidad" per se, sino con la forma dominante, hegemónica, "normal", de la masculinidad, que a partir del padecimiento de la violencia, y a pesar de la posibilidad de ejercicio de la misma, es vivida como opresora. El reconocimiento de las estructuras sociales internalizadas, presentes en la propia subjetividad y constitutivas de la misma, e incluso las estructuras sociales dominantes como habilitantes de determinadas formas de relaciones con los demás, generaron un distanciamiento, un rechazo, habilitaron un proceso de desidentificación, en la medida en que se ha tomado consciencia de "lo masculino", en su versión hegemónica, como dominante y opresiva. Al no querer reconocerse en esa imagen externa y socialmente valorada de lo masculino, la desidentificación abrió otros márgenes de agencia:

"Era permitirme aceptar la idea de que yo no era, ni podría ser nunca, el varón que llevara para ella la carga del macho inconmovible. Cinco años de psicoanálisis y una vesícula tardé en darme cuenta de eso" (Lautaro, 37 años).

"La posibilidad de abrirnos a otro tipo de relaciones más sanas y emocionalmente más enriquecedoras va a estar limitada por la pertenencia a la tribu, a la cual hay que serle fiel y mantener coherencia en sus códigos (...) escavar hasta vomitar en la previa del boliche, intentar 'comerse' a una 'mina,' pajearse de manera grupal con the film zone; ser y no ser constantemente 'ese' que representa lo que es y no es; lo que soy y no soy" (Francisco, 25 años). 
Si la identificación de género masculina, entonces, implicó el hacerse cargo de la totalidad de los efectos de ser representado como varón, la desidentificación, en cambio, puso en tensión, como dice Francisco, el ser y no ser constantemente "ese" que representa lo que es y no es; lo que soy y no soy (Francisco, 25 años), es decir, aquello mediante lo que uno es representado y se representa, aquello que uno no deja de ser pero ya no es del todo: es, y no es. La desidentificación implicó, para estos varones, de acuerdo con sus relatos, el reconocer lo operante del modelo hegemónico de lo masculino y cuestionar la omnipresencia de la violencia en los vínculos que habitar dicho género habilita.

En términos identitarios, podríamos decir que estos movimientos ponen de manifiesto la ambigüedad, la abertura y la ficción de las identificaciones de género. Por medio de la pregunta: ¿Soy varón?, ¿cómo, qué clase de varón 'soy'? (Sebastián, 23 años) estos varones denunciaron de las "censuras inherentes a las estructuras sociales" y se pusieron en tensión el mecanismo de interpelación ideológica de género y "el enorme poder simbólico inscrito en los cuerpos en su carácter de disposiciones" (Bourdieu, 2000, 23)

\subsection{Sexualidades en la (de)construcción masculina: desidentificaciones}

La instancia de la desidentificación con el modelo de masculinidad hegemónica implicó determinados movimientos, tensiones y desplazamientos y, en los relatos de estos varones, se caracterizó por el reconocimiento de la violencia intrínseca a la sociabilidad masculina. Sin embargo, se presencian dos tipos de relaciones con la violencia masculina. La violencia como categoría relacional implica que hay dos polos en dicho término: se la puede ejercer o se la puede padecer.

En este punto, la relación entre la sexualidad y el género se torna central, ya que estructura dos campos diferentes en función de la posición que se ocupe en la estructura de la violencia masculina: mientras que los gays relatan un sostenido padecimiento de la violencia (homofóbica) en reiterados ámbitos, los heterosexuales hacen énfasis en la tensión entre el padecimiento y el ejercicio. En este sentido, la vivencia de la sexualidad y la concordancia con la heteronorma plantea dos trayectorias de desidentificación diferentes que serán caracterizadas a continuación.

Es necesario aclarar que si bien en los relatos de los varones gays no hay mención al ejercicio de la violencia, esto no significa ni que los gays no ejerzan violencia ni que estos varones no hayan tenidos actitudes agresivas en algún momento de sus vidas, sino solamente que nos llamó la atención el lugar que ocupa la violencia en los relatos de los varones heterosexuales y de los varones gays.

\subsubsection{Gays, heteronormatividad y la violencia recibida}

En los relatos de los varones, aquellos con orientaciones sexuales homosexuales cuentan cómo padecieron violencia desde edades tempranas.

"Ya en 7 mo y los años posteriores, otra vez me vi amenazado por personas mayores que yo. Pequeñas amenazas, insultos constantes, bromas, dedos señalándote cuando había que elegir al mariposón de la primavera, y todo eso" (Nahuel, 18 años).

"Primero era dejado de lado por puto, o más que por puto, por afeminado. Después lo intelectual sirvió para ser más nerd que trolo y sobreponerme y relacionarme desde otro lado con la gente" (Sebastián, 23 años). 
Si bien estas violencias fueron padecidas mucho antes de que la identidad sexual estuviera conformada, es decir, efectivamente antes de que estos sujetos se autodesignaran como gays, ya en la niñez se constata la presencia de pulsiones sexuales homoeróticas, y su correspondiente represión en distintos períodos.

"Recuerdo que durante mis 6 y 7 años empecé a descubrirme, mi cuerpo y mis impulsos. Besaba compañeritos, los tocaba. No sé realmente por qué lo hacía, pero simplemente reproducía creo lo que veía. Ya me sentía atraído por varones" (Nahuel, 18 años).

El padecimiento de la violencia masculina favoreció una desidentificación de carácter temprano, ya que desde las primeras edades se entró en contacto con a) las exigencias al modelo hegemónico de lo masculino; b) los mecanismos de control y castigos que se ponen en funcionamiento cuando se ensaya la separación o la distancia con dicho modelo. En tal sentido, la norma masculina solo es vivida como coercitiva cuando se intenta escapar a sus efectos, mientras se esté diligentemente dentro de ellos, dicha coerción se reviste con una suma de privilegios que deben ser defendidos sobre la base de la violencia intrínseca de la masculinidad.

En el relato de estos varones es crucial el momento de asunción de la identidad sexual, en este caso como gays. El hecho de que el momento de la asunción de la identidad gay esté estrechamente vinculado a la "salida del clóset", es decir, a la presentación de tal situación ante "la sociedad" y puntualmente condensada en la figura de los padres, como primeros representantes de la sociedad y la cultura en la psique infantil, merece una investigación propia. Sin embargo, citaré un fragmento de la experiencia de uno de los relatos, ya que pone en evidencia la relacionalidad y parcialidad de las identidades, en el sentido de que vienen de los otros y se asume ante la mirada de los otros:

"Elegí el día de mi cumpleaños para decirles, terminaron de cantarme el feliz cumpleaños, toda mi familia presente, me paré y les dije 'tengo algo que decirles: soy gay.' Fue lo mejor. Estaba muy nervioso, era peor que haber actuado en público. Llantos, sonrisas, abrazos. Todxs diciéndome que me querían. (...) Al otro día mi viejo renunció al laburo y se fue a trabajar a otra provincia" (Nahuel, 18 años).

\subsubsection{Construcción de la masculinidad heterosexual en el ejercicio de la violencia}

En los relatos de los varones heterosexuales su relación con la violencia (masculina) se expresa o se manifiesta de manera diferente por tanto que no solo la padecieron sino que también la ejercieron. La tensión entre el ejercicio y el padecimiento de esa forma de violencia está dada en la medida en que la violencia se manifiesta como un lenguaje afectivo, ligado a la pertenencia a determinado grupo social, ligado a la aceptación y a la integración en un grupo de pares, conformado por otros varones "heterosexuales", en la niñez y la adolescencia principal pero no únicamente.

Lo interesante de aquellos que ejercieron o detentaron la violencia como mecanismo para garantizar la identificación masculina hegemónica es que en su interior también coinciden con quien la padece, es decir, la medida de la violencia ejercida a los otros está dada por la violencia ejercida sobre sí mismos, sobre la represión de la propia pulsión homosexual, presente en todo sujeto. Podríamos homologar la situación de la heterosexualidad con la famosa frase de Simone de Beauvoir para decir que heterosexual no se nace, sino que se deviene heterosexual. En tal sentido la heterosexualidad es caracterizable como un régimen político (Wittig, 1992). 
"Amo y odio a mis hermanos, mejoden todo el tiempo, gordo, cabezón, maricón; me habilitan el 'mundo de los de afuera', los juegos, la aventura, la violencia, la humillación... pero prefiero los videojuegos y dibujitos. Soy un pequeño Demian en un mundo de adultos, queriendo esconderme de la violencia, pero siendo el primero en ser encontrado cuando jugamos a las escondidas (...) Pero en la escuela no!, no quiero ser el menor. Me peleo, escupo, insulto por un lado; por el otro, dibujo, canto, juego con figuritas (...) Cartas pornográficas, chanchifutbol, 'chupapija'y 'maricón.' Le bajo -me bajan- la cabeza lo más abajo posible -me duele mucho el cuello-, ipete!, gritamos. Jugar a la violencia sexual, todos los días" (Francisco, 25 años).

"El cumpleaños de 18 de Lauta y todos decidimos llevarlo a 'las putas.' En un prostíbulo del centro nos creemos los dueños de algo similar a un arma, nos reímos de la travesti que atiende el lugar, nos reímos de los hombres que están ahí, de las mujeres 'feas' que 'trabajan' ahí, nos reímos de todo menos de nosotros mismos (...) Me retraigo lo más posible pero sin salir del papel designado por la tribu (...) La regla es confiar en la tribu, aun cuando esta te haga mal, o le haga mal a lxs demás. Reís hasta llorar, pero nunca llorar de verdad"(Francisco, 25 años).

El rol de los "demás hombres", de los compañeros de tribu, es clave en la conformación de la identidad masculina y es clave para el sostenimiento del modelo hegemónico. Este fenómeno ha sido designado con el nombre de validación homosocial (Kimmel, 1999) y refiere a la fórmula de la relacionalidad de la virilidad de Bourdieu, cuando este sostiene que la virilidad es un atributo para los demás hombres (Bourdieu, 2000).

\subsubsection{Lo femenino y lo artístico: refugio y resistencia}

Todos los varones de nuestra muestra relatan tener identificaciones con lo femenino. En este punto, la identificación no es necesariamente el sentido psicoanalítico propiamente dicho con el que se habla en el resto de texto de identificación/desidentificación y más adelante, reidentificación, en tanto incorporación de algunos de los rasgos del objeto, sino en un sentido amplio, en el sentido de afinidad:

"En mi vida, la figura femenina representada en muchas personas, hermanas, madre, amigas, vecinas, era más fuerte y me transmitía más confianza. Y esa dicotomía Hombre = frialdad y miedo/Mujer = amory cariño empezó a internalizarse en mi mente (...) Llegué a 6to grado con pocas ganas de tratar de cambiar el mundo. Con amory cariño solo para mujeres. Cálido y reconfortante. Femenino. Ajeno a todo lo que la 'masculinidad hegemónica' representa. Me parece que en el transcurso de mis años pude formar esa coraza que hace que pueda subsistir en el entorno sin tener que modificar mis actos y pensamientos 'privados.' No tenía amigos, y tenía amigas, las cuales mi madre me prohibía verlas, ya que yo era nene y tenía que jugar con otros nenes" (Nahuel, 18 años).

Según las lógicas de la masculinidad hegemónica, la afinidad con lo femenino implica una ruptura con el repudio hacia lo femenino, implica una traición a la "auténtica virilidad". Esta forma de violencia se expresa principalmente como homofobia. En un contexto de heternormatividad, la afinidad con lo femenino restringe la identificación con el modelo hegemónico masculino y habilita múltiples identificaciones de género en el orden de las subjetividades.

Junto con el reconocimiento de las tensiones entre el ejercicio y el padecimiento de la violencia patriarcal, la desidentificación, en el caso de los relatos de los varones heterosexuales, está favorecida por sus afinidades, identificaciones en sentido amplio, con lo femenino, por el descubrimiento de las dimensiones artísticas así como por las relaciones amatorias con mujeres, principalmente feministas. 
"A su vez me entendía mejor con las mujeres desde que tengo recuerdos, eso me hacía ver lo femenino en míy en los varones que me rodeaban, de ellas aprendi a ser lo que soy y quiero ser" (Samuel, 25 años).

"Llega el Magisterio y mis 15 años. Recuerdo que en este cumple mis amigas del DAD me regalan un vestido rosado hecho de papel crepé y lentejuelas; considerado como un chico 'sensible', ellas me veían y me trataban como su amiga, y eso me hacía sentir querido y valorado por lo que soy" (Francisco, 25 años).

De este modo, tanto la compañía de mujeres como lo femenino propio de cada sujeto es potencialmente un espacio de refugio de la hegemonía masculina, que puede devenir resistencia en la medida en que se rompe o se cuestiona el repudio hacia lo femenino que dicha norma sostiene.

En el caso del descubrimiento de las expresiones artísticas, estas funcionan como válvula de escape ante la demanda de ejercicio de violencia, como carta de presentación también ante otras subjetividades no identificadas con las masculinidades hegemónicas.

"Llegan ríos llenos de cuentos, poesías, llevo mi cuaderno de poemas para todos lados, que funciona a su vez como credencial de -no soy un mero machote violento-para entablar otro tipo de relaciones. La endogamia empieza a resquebrajarse, empiezo a criticar, a cuestionarme, interesarme por lo social. Quiero decir lo que pienso y lo que siento, quiero criticar lo violento y al violento, ignorarlo o alejarme de él (...) La tribu se siente traicionada y me excluye por romper con su coherencia machista" (Francisco, 25 años).

"(...) mis inquietudes empezaron a verse reflejadas en los libros que empezaba a leer, en el cine que empezaba a ver y en la música que empezaba a sentir. Eso me llevó a acercarme de otra manera a los varones, de una forma mucho más abierta, creyéndome personajes de libros como Demian de Herman Hesse, por decir uno jaja. De esa manera entablar relaciones con esos varones que yo veía no seguían el juego de los golpes y la brusquedad o si lo hacían se les notaba que era forzado" (Samuel, 25 años).

El encuentro sexo-afectivo con mujeres puede implicar una reafirmación de la identificación con el modelo hegemónico, en términos de complementariedad sociopsicosexual de los géneros, en el marco de la heteronorma, de modo que la violencia se reactualiza: ya no es el grupo de pares quien ejerce la violencia sino que es la pareja sexual la que demanda una posición identificada, y su correspondiente vínculo con la violencia hacia sí mismo y hacia los demás, como así también su vínculo con el honor, con el trabajo, con la potencia, con el proveer.

"Laura, bella encarnación de todas las normatividades femeninas (... ejerció sobre mí todo tipo de violencias, buscando en el lugar del hombre que yo intenté ocupar, los significantes complementarios de su personaje, demandando una envestidura de poder, de carácter y de ley que no admitía titubeos" (Lautaro, 37 años).

Sin embargo, los encuentros amistosos y sexoafectivos con mujeres feministas favoreció la desidentificación, debido a la problematización y a la politización de las relaciones sexoafectivas de dichas mujeres.

"Finalmente encontré a 'Fulana', la mujer más maravillosa e irritante que conozco. Feminista primero y socióloga después, sus comentarios sobre la opresión de las mujeres por parte de los hombres, o sobre la construcción de las identidades sexuales, cortaban como una cizalla todo lo que había aprendido a través de la experiencia y hacían tambalear mis hipótesis de 
que las mujeres, desde el conveniente lugar de víctimas, manipulaban a los hombres para ejercer poder sobre diversos ámbitos" (Lautaro, 37 años).

"A los 20 años conocí a una de las mujeres más hermosas que pasó por mi vida, con la que caminamos juntos, crecimos (...) ella fue mi ex, feminista ella. La razón por la que ingresé en el Colectivo de varones, y por eso la describo tanto" (Samuel, 25 años).

De este modo, la sexualidad de estos varones, gays y heteros, los posicionó en lugares diferentes en relación con los otros varones, ergo, con la posibilidad de ejercicio de la violencia patriarcal o con la forma de padecimiento de la misma. Esto confirma lo que sostiene De Lauretis cuando dice que la tarea del género es reprimir lo sexual (De Lauretis, 2014).

A continuación veremos en qué momento surge el espacio del Colectivo de Varones Anti-Patriarcales y cómo permite conjugar las distintas formas de desidentificación con la denuncia concreta de un modelo hegemónico de identidad masculina y cómo se articula dicha denuncia con una forma concreta de participación política feminista.

\section{3. (De)construir la masculinidad en la participación política y la reflexión colectiva: reidentificaciones}

El encuentro con subjetividades sexoafectivamente en politización y problematización favorece, por un lado, el reconocimiento de la normatividad del modelo hegemónico de lo que lo masculino es y debe ser actuante en la propia trayectoria y, por el otro, un encuentro intersubjetivo que abre a nuevas tensiones la sujeción de la subjetividad a una esfera ideológica. En pocas palabras: siembra la pregunta qué es ser varón, qué significa ser varón para sí: "¿Soy varón?, ¿cómo, qué clase de varón 'soy'?" (Sebastián, 23 años).

En estos procesos de desidentificación y reidentificación, el Colectivo de Varones AntiPatriarcales, desde sus consignas de problematización de las dimensiones personales (sociopsicosexuales) como políticas y politizables, funciona como un espacio de encuentro y de reidentificación de una "masculinidad" puesta entre comillas, ya que se cuestionan los cimientos de aquel modelo hegemónico.

"Participo en luchas sociales (...) de mirar con los ojos de Ixs otrxs, de repensar y re-sentir mi sexualidad y mi identidad, sentir una unión como con plasticola por todos los cuerpos y todos los sexos, acá, adentro suyo, (...) soy hetero no normativo atraído por brujas, gitanas y ninfas del bosque, me siento otrx, sabiendo que quien me atrae es otrx, como yo, inclasificable incosificabe" (Francisco, 25 años).

Podríamos decir que se da una inversión de la fórmula "Relacionalidad de la 'masculinidad': con otrxs sujetxs, gracias a lo femenino y contra lo masculino hegemónico". Esta fórmula no funciona como una última reidentificación, sino que más bien habilita el sostenimiento de la tensión entre la identificación con una masculinidad de la que previamente se ha renegado y de la que se continúa renegando, pero de la que también se plantea imposible el escape.

La inversión del repudio implica que se vuelve contra sí mismo, contra las propias dimensiones hegemónicas y los propios privilegios que los constituyeron y lo siguen constituyendo a uno como varón.

El descubrimiento de la relación con la violencia, contra los demás y contra uno mismo, habilita reconociendo el desamor como elemento central en el ejercicio de la masculinidad, 
en el encuentro con la propia vulnerabilidad profunda que implica haber sido socializado varón y dar en la medida de las constantes exigencias que el modelo hegemónico imparte, que suponen negar y reprimir ese núcleo de vulnerabilidad, incluso a costa de uno mismo. La exaltación de los valores masculinos tiene su tenebrosa contrapartida en los miedos y las angustias que suscita la feminidad (...) Todo contribuye así a hacer del ideal imposible de la virilidad el principio de una inmensa vulnerabilidad (Bourdieu, 1999, 69).

"Atravesar ese camino (de deconstrucción de la masculinidad en psicoanálisis) es muy diferente a encarar un proceso de reflexión colectiva, donde imagino que el crecimiento entre pares podrá existir solo gracias a un fuerte compromiso con la autorreflexión, con la formación mediante lectura colectiva de textos, y especialmente con la construcción de vínculos, de confianza, que considero la punta del ovillo para que lo personal pueda ser puesto en palabras y una vez compartido, devenga quizás en político" (Lautaro, 37 años).

"Aún siento que en esta felicidad no hay nada dicho... está todo por contarse, por vivirsey por sentirse, y eso me hace ser. Un punto de partida, y no de llegada -qué punto ni punto, espiral!-. Gracias por comenzar este viaje conmigo, con una parte muy importante de esta felicidad... Colectivamente, el amor es abundante-basta de regirnos por la escasez!!- de ahí radica la fuerza política de lo que estamos formando y el amor es todo lo que necesitamos" (Francisco, 25 años).

En este sentido, la reflexión colectiva de los propios procesos de socialización se vuelve un acto amoroso y un manifiesto político de encuentro intersubjetivo y establece otras bases para la práctica política, a partir de poner en juego las tensiones abiertas con la consigna feminista "lo personal es político", a lo que los Colectivos de varones en su devenir han agregado "y lo político, colectivo".

\section{CONCLUSIONES}

Las identificaciones de género en las trayectorias de estos sujetos fueron en un principio las de haber sido socializados como varones: estos sujetos asumieron los efectos de ser representados como tales. Si bien esta identificación no fue sin tensiones ni contradicciones, es un punto de partida estable que luego devino en desidentificación con el modelo de masculinidad hegemónico por diversos motivos.

La violencia atraviesa el total de estos relatos autobiográficos y delimita las relaciones específicas entre varones y con otros sujetos. Esta violencia, definida por Bourdieu como violencia simbólica (Bourdieu, 2000), en los relatos toma formas particulares: violencia física, verbal, psicológica y sexual. Además, esta violencia es constitutiva de la identidad masculina en la medida en que la virilidad debe ser permanentemente (re)validada delante de otros hombres y en un repudio hacia lo femenino. Como en todo sujeto se da una síntesis más o menos armónica y más o menos aceptada de rasgos masculinos y femeninos (Laplanche y Polantis, 2015, 217-218), la violencia padecida se relaciona con el repudio hacia lo femenino, rasgos que fueron reprimidos más eficazmente por algunos sujetos, mientras que otros se identificaron con ello y encontraron allí un refugio ante esta violencia, que pudo devenir, luego, en una forma de resistencia.

Con la pregunta: ¿Soy varón?, ¿cómo, qué clase de varón 'soy'? (Sebastián, 23 años), podríamos decir que se pone de manifiesto la ambigüedad, la abertura y la ficción de las identificaciones de género, la que es a su vez producto y productora de movimientos y desplazamientos identitarios. 
Las relaciones entre identificaciones de género y sexualidades son complejas y significativas, ya que tanto la relación con las propias pulsiones, habiendo sido intensamente reprimidas en algunos casos, en algunos momentos, para luego ser "liberadas", como la relación con la elección de objeto sexoafectivo, en un contexto de heteronorma, definieron para estos varones diferentes recorridos y trayectorias identificatorias y sobre todo, desidentificatorias.

Por un lado, si bien aquellos varones autodefinidos como "gays"tuvieron una predisposición mayor hacia la represión de las pulsiones sexuales y hacia la conservación en la clandestinidad de dichas pulsiones, en momentos de la niñez y la adolescencia, el momento de "asunción" de la identidad homosexual representó una instancia de distanciamiento claro respecto del modelo de masculinidad hegemónica que sostiene que "el varón debe ser heterosexual". Por otro lado, las identificaciones tempranas con lo femenino propio de cada sujeto y con las mujeres, marcó una división que los puso en un lugar de claro padecimiento de diversas formas de violencia patriarcal, especialmente la homofobia, y que también significó un distanciamiento de las exigencias del modelo de masculinidad hegemónica.

Respecto de los heterosexuales, en sus trayectorias desidentificatorias hay puntos de encuentro y caminos propios acerca de los no heterosexuales: en relación con la violencia, los relatos de los sujetos autodefinidos hasta ese momento como heterosexuales enfatizan la ambigüedad entre el padecimiento, encarnado en "la tribu"y los grupos de pares, y el ejercicio de la violencia, destinado no solo a la pertenencia a un grupo de "hombres auténticos", sino también a marcar la división con las "otras" subjetividades. Esto llevó a vivir el distanciamiento de ciertos grupos como una ruptura contra la norma hegemónica de la masculinidad, en pos de buscar alternativas a esa masculinidad. Estas alternativas fueron encontradas en dimensiones asociadas a lo femenino: las dimensiones afectivas, expresivas y artísticas, por un lado, y en las mujeres, por el otro. Respecto de su relación con las mujeres, mientras algunos vínculos sexoafectivos disponían a la reproducción de los roles binarios heterosexuales de la norma hegemónica, otros vínculos amistosos y amorosos con subjetividades con trayectorias en la "politización" de las identidades sexuales, representadas principal pero no exclusivamente en "las compañeras feministas", interpelaron y habilitaron formas alternativas de vivir la propia masculinidad.

De estos modos heterogéneos, con puntos de encuentro y de diferenciación, las trayectorias de desidentificación de estos sujetos están caracterizadas por la profunda relación entre género y sexualidad.

Una característica que permitió volver este proceso de "deconstrucción" de la masculinidad sobre sí misma fue la reflexión colectiva y la participación política en el Colectivo de Varones Anti-Patriarcales. Las fuentes de datos de esta investigación fueron el resultado de una actividad concreta, el taller de autobiografías, que desarrolló el Colectivo, y por eso mismo el total de los relatos concluyeron con la presentación de los motivos y las expectativas que estos sujetos tuvieron en su participación en dicho espacio. Podríamos decir que se da una inversión de la fórmula "Relacionalidad de la "masculinidad": con otrxs sujetxs, gracias a lo femenino y contra lo masculino hegemónico", como resultado de la búsqueda de alternativas identificatorias que cuestionen y problematicen la violencia intrínseca a la masculinidad. Queda pendiente la corroboración o rectificación de si las prácticas y los procesos reflexivos de estos varones logran "realmente" deconstruir dicha violencia. Por los relatos solo podemos concluir que ese es el horizonte hacia el que se orienta su práctica. 
Hacia el final de los relatos, el énfasis está puesto en la necesidad de la amorosidad en la práctica política, como herramienta efectiva en contra de la violencia masculina. Además, esta afectividad se conjuga con la práctica colectiva y con la construcción de un nosotros, que si bien no es el "nuevo varón" o un "varón ya antipatriarcal", es una búsqueda alternativa y un corrimiento de lo que la representación hegemónica dice que lo masculino debe ser.

En conclusión, las relaciones entre la representación hegemónica de lo masculino y las subjetivaciones masculinas de los varones que participan del Colectivo de Varones AntiPatriarcales de Mendoza son de desplazamientos en términos de las identificaciones de género, en función de su relación con las sexualidades. La reflexión colectiva y la práctica política en dicho espacio, representado en el taller de autobiografías, se manifestaron como parte de un proceso de desidentificación de la hegemonía, así como también plantearon la necesidad de nuevas instancias identificatorias que deconstruyan la masculinidad hegemónica.

\section{BIBLIOGRAFÍA}

Althusser, Louis (1971): Aparatos Ideológicos de Estado, Fondo de Cultura Económica.

Arfuch, Leonor (2010): El espacio biográfico. Dilemas de la subjetividad contemporánea. Fondo de Cultura Económica, Buenos Aires.

Beauvoir, Simon de (1995): El segundo sexo, México, Siglo Veinte.

Bonino Mendez, Luis (1998): Deconstruyendo la 'normalidad' masculina. Apuntes para una 'psicopatología' del género masculino, Madrid. Disponible en: http://www.europrofem.org/ contri/2_05_es/es-masc/22es_mas.htm

Bourdieu, Pierre (2000): La dominación masculina, Anagrama, Barcelona.

Butler, Judit (2001): El género en disputa. El feminismo y la subversión de la identidad, Buenos Aires, Paidós.

De Lauretis, Teresa (1996): "La tecnología del género” en Mora, № 2, Buenos Aires.

De Lauretis, Teresa (2014): Conferencia, Buenos Aires, 2014. en: https://www.youtube.com/ watch?v=SY_5x0BdIFk\#t=3306.

Kimmel, Michael (1999): "Homofobia, temor, vergüenza y silencio en la identidad masculina”, en Valdez, Teresa y Olavarría, José, Masculinidad/es: poder y crisis, Cap. 3, ISIS-FLACSO: Ediciones de las Mujeres, № 24, pp. 49-62, 1999.

Laplanche, Polantis (2015): Diccionario de psicoanálisis. Buenos Aires. Paidós.

Wittig, Monique (1992):"El pensamiento heterosexual y otros ensayos", Madrid, Editorial EGALES. 